\title{
Os Novos Túneis Urbanos da Cidade do Recife: Casos de Degradação Prematura de Estruturas de Concreto
}

\author{
The New Urban Tunnels on the city of Recife: Cases of premature degradation on \\ structures of concrete
}

Eduardo José Melo Lins ${ }^{1}$ (i) orcid.org/0000-0001-8347-6183

Ramon Duque Ferraz Burgos ${ }^{1}$ (D) orcid.org/0000-0001-8807-7544

Eliana Cristina Barreto Monteiro ${ }^{2,3}$ (iD) orcid.org/0000-0003-0842-779X

${ }^{1}$ Programa de Pós-graduação em Manutenção, Inspeção e Recuperação de Estruturas Universidade de Pernambuco, Recife, Brasil,
2 Departamento de Engenharia Civil, Universidade de Pernambuco, Recife, Brasil,
${ }^{3}$ Departamento de Engenharia Civil, Universidade Católica de Pernambuco, Recife, Brasil.

E-mail do autor principal: Eduardo Lins eduardojmlins@hotmail.com

Resumo

A realização da manutenção preventiva torna possível a identificação de manifestações patológicas e evita a redução do desempenho da estrutura, porém a cultura da manutenção em obras públicas no Brasil não é devidamente adotada, no caso dos túneis, intensificada pela falta de uma norma específica para a inspeção de túneis urbanos. Na cidade do Recife não é diferente, dos cinco túneis existentes na área urbana, todos apresentam sinais de deterioração e suas condições preocupam os usuários, o que se agrava pela cidade do Recife se encontrar num ambiente bastante agressivo, com alagamentos constantes e nível do lençol freático alto. Este estudo tem como objetivo analisar o Túnel da Abolição e Túnel Felipe Camarão, os quais foram os últimos a serem construídos. Após a inspeção, ficou claro que o estado de conservação dos túneis é preocupante e que manifestações patológicas estão presentes em ambas as estruturas dos túneis inspecionados. Os dois túneis mais recentemente construídos apresentam degradação acelerada e prematura de boa parte da estrutura. Medidas corretivas são necessárias e de responsabilidade do poder público, caso contrário a estrutura deixará de atender à finalidade para a qual foi concebida, podendo causar risco à integridade física dos cidadãos que as utilizam.

Palavras-Chave: Túneis; Durabilidade; Patologia; Recife; Concreto;

\begin{abstract}
The performing of preventive maintenance makes it possible to identify pathological manifestations and avoids a reduction in the performance of the structure, but the culture of maintenance in nonpublic works in Brazil is not properly adopted in the case of tunnels, intensified by the lack of a specific standards for Inspection of urban tunnels. In the city of Recife is no different, all the five tunnels in the urban area, has signs of deterioration and its conditions worry the users, which is aggravated by the location of the city of Recife in a very aggressive environment, with constant flooding and the high level of the subterranean water. This study aims to analyze the Abolition Tunnel 157

http: / / dx.doi.org/10.25286/repa.v2i3.712
\end{abstract}


and Felipe Camarão Tunnel, which were the last to be built. After the inspection, it became clear that the state of conservation of the tunnels is worrying and that pathological manifestations are present in both tunnels. The two most recently constructed tunnels have accelerated and premature degradation of much of the structure. Corrective measures are necessary and the responsibility are from the public power, otherwise the structure will no longer serve the purpose for which it was designed and may cause a risk to the physical integrity of the citizens who use them.

Key-words: Tunnels; Durability; Pathology; Recife; Concrete

\section{Introdução}

Até o ano de 2011 existiam 3 Túneis na Cidade do Recife. O primeiro construído foi o Túnel Prefeito Augusto Lucena, no Ano de 1997, e sua função principal seria desafogar o trânsito das vias arteriais nos arredores do bairro de Boa Viagem e facilitar o acesso ao bairro de Setúbal. O segundo túnel implantado foi o Chico Science, em 2000. Ele veio com a função de descongestionar um trecho crítico no encontro da Av. Abdias de Carvalho com a Av. Beira Rio e Rua da Benfica. No ano de 2007, foi concluído o túnel Josué de Castro, ou túnel do Pina, o qual ficou conhecido por ser a primeira obra que integraria a Via Mangue. Tais túneis citados acima foram objeto de estudo por DA FONTE [1], os quais realizaram inspeções visuais e buscaram caracterizar problemas estruturais e de manutenção que viessem a causar problemas aos utilizadores.

Porém, a Cidade do Recife sofreu forte impacto com a escolha para ser cidade sede da copa do mundo FIFA de 2014 e com a implantação do polo petroquímico no porto de SUAPE. Dois novos túneis foram projetados, o Túnel Felipe Camarão, com 300 m (984 pés) de comprimento, o qual foi subsidiado pelo Governo do Estado de Pernambuco e concebido para reduzir os congestionamentos no cruzamento das Avenidas Mascarenhas de Morais e Maria Irene, facilitando o acesso ao bairro do Jordão. O outro túnel planejado foi o Túnel da Abolição, o qual possui 287 m (941 pés) e fica localizado no cruzamento da Rua Real da Torre com a Rua da Benfica e integra parte da implantação do corredor Leste-Oeste.

Os dois túneis são de construção recente, tendo o primeiro sido construído há cinco anos, porém, apesar de serem novos, apresentam manifestações patológicas de mesmo grau de risco e intensidade que os três mais antigos. Eles são de grande importância para o trânsito da cidade, visto que o Recife consta como a cidade com o oitavo pior trânsito do mundo [2], e a interrupção do tráfego em algum deles iria causar diversos problemas de mobilidade.

A manutenção preventiva pode evitar que os túneis fiquem em estado crítico de utilização e que o custo de recuperação possa vir a ser até 50 vezes mais caro que o da manutenção, porém não há uma cultura de manutenção preventiva nos órgãos responsáveis pelos túneis do Recife, fazendo com que as intervenções acorram após acidentes automobilísticos, os quais por vezes são fatais. Tal fato não está muito distante dos túneis do Recife, pois já houveram acidentes provocados por alagamentos e pela falta de iluminação na parte interina dos túneis. Uma vez que não há notícias oficiais a respeito da existência de planos de manutenção ou inspeções periódicas para a análise do estado das estruturas que compõem os túneis da cidade do Recife, o presente artigo científico tem o objetivo de analisar e diagnosticar preliminarmente a atual condição das estruturas e identificar os fatores e as causas da visível deterioração prematura e acelerada dos dois túneis mais recentemente construído na cidade do Recife, quais sejam, o Túnel Felipe Camarão e o Túnel da Abolição.

\section{Manutenção e vida útil das estruturas de concreto}

SOUZA e RIPPER [3] definem a manutenção de uma estrutura como sendo o conjunto de atividades necessárias para a garantia do seu desempenho satisfatório ao longo do tempo, ou seja, o conjunto de rotinas que tenham por finalidade o prolongamento da vida útil da obra. Também é ressaltado que um bom programa de manutenção implica na definição de metodologias adequadas de operação, controle e 
execução da obra. UEDA e TAKEWAKA [4] demonstram a importância econômica da manutenção na durabilidade da estrutura, com as diferenças de gastos entre manutenção e reparo, conforme apresentado no Quadro 1.

Quadro 1: Gastos em Países desenvolvidos com manutenção e reparo

\begin{tabular}{|c|c|c|c|}
\hline Pais & $\begin{array}{c}\text { Gastos com } \\
\text { construçôes novas }\end{array}$ & $\begin{array}{c}\text { Gastos com } \\
\text { manutenção e reparo }\end{array}$ & $\begin{array}{l}\text { Gastos totais com } \\
\text { construção }\end{array}$ \\
\hline França & $\begin{array}{c}85,6 \text { Bilhões de Euros } \\
(52 \%)\end{array}$ & $\begin{array}{c}\text { 79,6 Bilhões de Euros } \\
(48 \%)\end{array}$ & $\begin{array}{c}\begin{array}{c}165,2 \text { Bilhões de Euros } \\
(100 \%)\end{array} \\
\end{array}$ \\
\hline Alemanhã & $\begin{array}{c}99,7 \text { Bilhões de Euros } \\
(50 \%)\end{array}$ & $\begin{array}{c}99,0 \text { Bilhões de Euros } \\
(50 \%)\end{array}$ & $\begin{array}{c}198,7 \text { Bilhões de Euros } \\
(100 \%)\end{array}$ \\
\hline Itália & $\begin{array}{c}58,6 \text { Billhōes de Euros } \\
(43 \%)\end{array}$ & $\begin{array}{c}\text { 76,8 Bilhōes de Euros } \\
(57 \%)\end{array}$ & $\begin{array}{c}\text { 135,4 Bilhöes de Euros } \\
(100 \%)\end{array}$ \\
\hline Reino Unido & $\begin{array}{l}\text { 60,7 Bilhões de Pounds } \\
(50 \%)\end{array}$ & $\begin{array}{c}61,2 \text { Bilhões de Pounds } \\
(50 \%)\end{array}$ & $\begin{array}{c}\text { 121,9 Billōes de Pounds } \\
(100 \%)\end{array}$ \\
\hline
\end{tabular}

Fonte: UEDA E TAKEWAKA (2007)

Fica evidente que a manutenção das estruturas de concreto armado é economicamente mais vantajosa que a recuperação, e que as inspeções periódicas são de grande importância para a verificação e correção de manifestações patológicas, prolongando a vida útil da estrutura.

A manutenção pode ser associada com outro fator de conservação importante para as estruturas de concreto armado, a vida util. A ABNT NBR 6118:2014 [5], define a vida útil de projeto como sendo o "período de tempo durante o qual se mantêm as características das estruturas de concreto, desde que atendidos os requisitos de uso e manutenção prescritos pelo projetista e pelo construtor".

No Brasil há uma proposta de definição clara de vida útil de projeto desde o início da década de 90 [6], limitada aos fenômenos de corrosão das armaduras, que pode ser esquematizado conforme mostrado na Figura 1. Para os demais fenômenos de deterioração ainda não há propostas brasileiras nem internacionais [7].

Existe uma proximidade entre os conceitos de vida útil e durabilidade que, às vezes, leva à utilização equivocada dos termos. Pode-se considerar que a vida útil é a quantificação da durabilidade que se supõe ser apenas uma qualidade da estrutura. A vida útil pode também ser entendida como o período de tempo durante o qual a estrutura é capaz de desempenhar bem as funções para as quais foi projetada.

Os problemas patológicos ocasionados por manutenção inadequada, ou mesmo pela ausência total de manutenção, têm sua origem no desconhecimento técnico, na incompetência, no desleixo e em problemas econômicos. A falta de alocação de verbas para manutenção pode vir a se 159 tornar um fator responsável pelo surgimento de problemas estruturais de maiores proporções, implicando gastos significativos e, no limite, a própria demolição da estrutura [3].

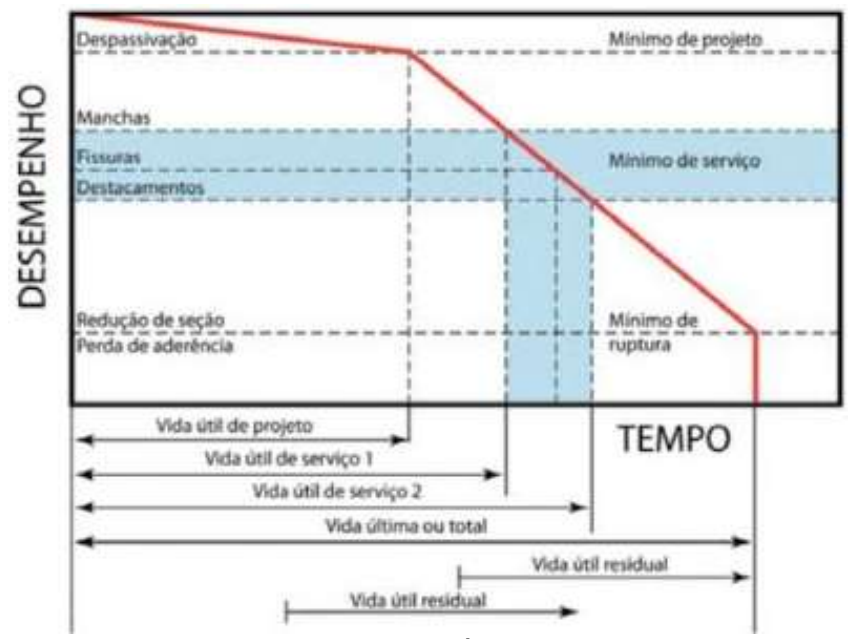

Figura 1: Conceituação de vida útil das estruturas de concreto tomando por referência o fenômeno de corrosão de armaduras. Fonte: HELENE (1997)

LEMOS [9] comenta que a maior parte da bibliografia existente relata principalmente danos e degradação nas estruturas subterrâneas causadas pela infiltração de água. Estes danos são classificados de acordo com ITA [10] em três diferentes categorias: Efeitos externos (no entorno do túnel, mas não afetando sua estrutura), efeitos estruturais (afetando a capacidade estrutural do túnel) e efeitos funcionais (afetando a funcionalidade do túnel).

O Manual de Inspeção de Obras-de-Arte Especiais do DNER [11], também lista os principais efeitos dos problemas patológicos que conduzem à deterioração das estruturas, são eles:

- Degradação da aparência da estrutura em função das manchas, eflorescências, estalactites e fissuras no concreto, além de deformações excessivas na estrutura;

- Perda da rigidez e resistência da estrutura em função da presença de fissuras, do destacamento ou desagregação do concreto ou de corrosão de armaduras;

- Diminuição da vida útil da estrutura, quando os efeitos anteriormente citados atingem um nível de comportamento que impede a continuação do uso da estrutura.

Segundo DA FONTE [1], existe uma forte necessidade de se implantar sistemas de manutenção em obras de qualquer nível ou tipo de utilização, no

http: / / dx.doi.org/10.25286/repa.v2i3.712 
caso de obras públicas, mais especialmente os túneis. A questão da manutenção se torna ainda mais importante porque há grande circulação de usuários, que leva a uma degradação natural do equipamento e tendo em vista que são estruturas fechadas, as mesmas ficam submetidas a fortes ações agressivas como as infiltrações e subpressões.

Essa deficiência na manutenção dos túneis se deve em parte à escassez de normas brasileiras específicas para a manutenção de túneis, havendo normas apenas para as situações de incêndio.

LEMOS [9], cita a experiência de outros países no quesito manutenção e reabilitação das estruturas dos túneis. Na República Tcheca túneis rodoviários recebem as inspeções duas vezes ao ano, com inclusão de inspeções especiais quando necessário. São verificados o estado do suporte, a presença de fluxo de água, trincas visíveis e medidas de temperatura. Vale ressaltar que no mesmo país a frequência nas inspeções em túneis de metrô é semanal, mensal e anual.

No Japão, as inspeções do sistema de suporte de túneis são divididas em inspeção primária e secundária. Novas tecnologias de inspeção nãodestrutivas estão sendo utilizadas, entre elas veículos equipados com sistemas de georadar e câmeras de infravermelho que executam inspeções rápidas [9].

No Brasil, de um modo geral, os túneis pertencem às malhas rodoviárias/ferroviárias federais, estaduais ou municipais, de modo que as manutenções de tais equipamentos são realizadas por essas três instâncias de poderes através de órgãos públicos ou por meio de concessionárias. Esta última, com a implantação nos últimos anos no Brasil da política de concessões de rodovias, torna-se a gerenciadora das manutenções dos túneis existentes nesses trechos, criando técnicas específicas de acordo com o sistema construtivo de cada túnel. No caso das rodovias que continuam sob a gestão pública percebe-se que ainda existe uma grande deficiência de manutenção, gerada pela falta de recursos e também por uma cultura que prioriza a construção de obras novas em detrimento da conservação de obras existentes [1].
Para a elaboração do presente artigo foram realizadas inspeções no período de chuvas do Recife, mais precisamente nos meses de maio e junho de 2017. De acordo com o boletim de acúmulo de precipitações da Agência Pernambucana de Águas e Climas (APAC), o mês de maio apresentou um acúmulo de chuvas com 282,2 mm e o mês de junho com 284,9 $\mathrm{mm}$, volumes de chuva elevados, o que aumenta o contato das estruturas com a água e, favorece o desenvolvimento das manifestações patológicas em estruturas de concreto subterrâneas.

As inspeções foram realizadas de forma visual, com o auxílio de um fissurômetro, câmera fotográfica e uma trena. Com os dados obtidos nas inspeções, foram desenvolvidos quadros com o mapeamento das manifestações presentes, segundo o modelo proposto no trabalha de DA FONTE [1]. Para a busca de informações relevantes, e potencialmente influenciadoras das condições de conservação e manutenção dos túneis, foram utilizadas buscas no banco de dados do Google Scholar, Scielo e Portal de Periódicos da Coordenação de Aperfeiçoamento de Pessoal de Nível Superior/Ministério da Educação (CAPES/MEC).

\section{Resultados}

\subsection{Túnel da Abolição}

O túnel da Abolição fica localizado na Rua Real da Torre e passa sob a Rua da Benfica. Ele possui $287 \mathrm{~m}$ e é o túnel mais novo construído na Cidade do Recife, tendo sido concluído em 2015. O túnel foi prejudicado por um erro de projeto que o encolheu meio metro entre o desenho e a execução. O equipamento previa três faixas de rolamento, sendo uma delas exclusiva para o transporte público. E, para isso, deveria ter no mínimo 8,90 de largura, mas ficou com apenas 8,40, inviabilizando a terceira via e a utilização de uma parada de ônibus dentro do túnel. Apesar dessa inviabilidade, ainda foram construídos dois acessos ao subterrâneo do túnel: Uma escada e a estrutura metálica para receber um elevador. O Quadro 2 define às características do túnel.

\section{Metodologia}


Quadro 2: Características do Túnel da Abolição

\begin{tabular}{|c|c|}
\hline Ano de Construção & 2015 \\
\hline Localização & Madalena, Recife - PE \\
\hline Tipo de Túnel & Urbano \\
\hline Proprietário & Prefeitura do Recife \\
\hline Extensão & $324,00 \mathrm{~m}$ \\
\hline Largura & $8,80 \mathrm{~m}$ \\
\hline Altura Limite & $5,60 \mathrm{~m}$ \\
\hline Quantidade de Faixas & Duas Faixas/Sentido \\
\hline Sentido de Fluxo & Sentido Único (Norte-Sul) \\
\hline Material & Concreto armado \\
\hline Forma & Semienterrado \\
\hline Contenções Laterais & Estacas Secantes \\
\hline Tipo de Juntas & Jeene \\
\hline Tipo de Pavimentação & CBUQ \\
\hline \multicolumn{2}{|c|}{ Fonte: Dos Autores (2017) } \\
\hline
\end{tabular}

No dia da inspeção a APAC registrou 49,6 mm de chuva. O Túnel da Abolição se diferencia por ter a parede de contenção construída com estacas secantes com diâmetro nominal de $600 \mathrm{~mm}$. Essa tecnologia foi escolhida pelo baixo nível de vibrações emitidas, pois nos arredores do túnel existem construções históricas, a exemplo do Museu da Abolição, que dá nome ao referido túnel.

Na parte superior do túnel uma praça foi construída para integrar e valorizar os arredores do Museu da Abolição. Nesta praça existem sete canteiros elevados gramados, os quais no dia da inspeção apresentavam significativo acúmulo de água e manchas de percolação de água nas faces externas, como pode se verificar na Figura 2.

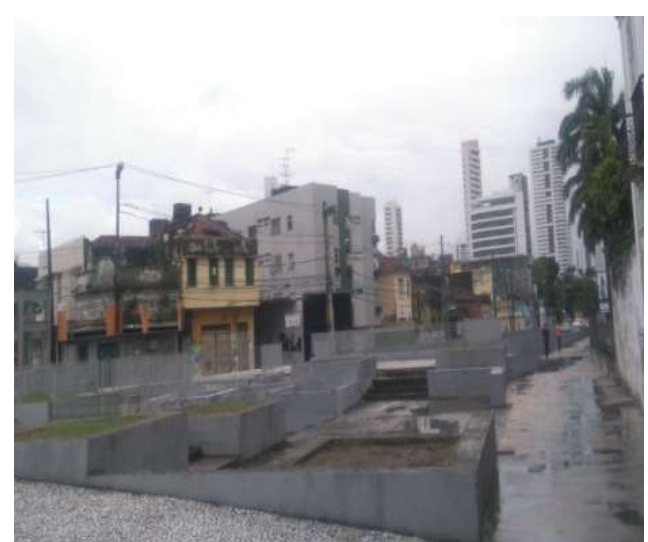

Figura 2: Praça sobre o túnel com pontos de alagamento Fonte: Dos Autores (2017)

Também se verificou água acumulada nas calçadas, nos patamares da escada de acesso ao subterrâneo e áreas centrais da praça. Nas calçadas existem sete ralos para permitir o escoamento das águas superficiais, porém cinco estavam entupidos e com a presença de vegetação em seu interior (Figura 3).

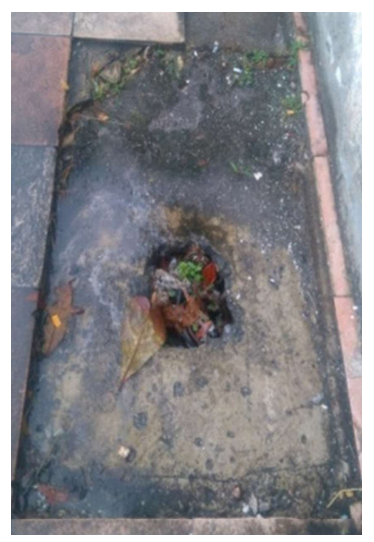

Figura 3: Estado dos ralos. Fonte: Dos Autores (2017)

$\mathrm{Na}$ área central da praça não há sistema de drenagem e a água apenas é direcionada para uma calha improvisada que deságua como uma cascata na faixa de rolamento da direita da parte interna do túnel, consequentemente atrapalhando a visão dos motoristas. Todos os problemas de manutenção identificados estão listados no Quadro 3. No túnel, verificou-se a presença fissuras tipo mapa e de percolação de água em toda a extensão da parede de contenção. É possível perceber que em boa parte dos pontos de percolação há presença de um material argiloso de cor alaranjada, além de pontos com eflorescência e criptoflorescência. O material argiloso apresenta consistência similar à argila, o qual provavelmente é advindo do carreamento de material do aterro lateral. Devido a umidade nas paredes de contenção, também verificamos a presença de arbustos de médio porte, lodo e pontos onde pequenos moluscos estavam fixos à parede.

Quadro 3: Problemas identificados por falta de manutenção no túnel da Abolição

\begin{tabular}{|c|c|}
\hline & Ano 2017 \\
\hline 1 & Drenos e ralos entupidos com acúmulo lodo \\
\hline 2 & Presença de vegetação e moluscos em toda a estrutura \\
\hline 3 & $\begin{array}{c}\text { Água escoando da Praça superior sobre a faixa de } \\
\text { rolamento central }\end{array}$ \\
\hline 4 & $\begin{array}{l}\text { Tubulação metálica do sistema de recalque com sinais de } \\
\text { corrosão }\end{array}$ \\
\hline
\end{tabular}

Fonte: Adaptado de DA FONTE (2011)

Nas paredes de contenção há vigas de coroamento em concreto armado para amarração das estacas secantes. Duas cintas ficam na parte central das paredes e uma na extremidade superior das mesmas,

http: / / dx.doi.org/10.25286/repa.v2i3.712 
as quais também servem como guarda corpo para os pedestres que trafegam por cima do túnel. Nas duas cintas de coroamento centrais há a presença de nichos de concretagem de dimensões consideráveis e armaduras aparentes com sinais de corrosão. A Figura 4 mostra o estado avançado de corrosão da armadura, além de outras manifestações patológicas dispostas no Quadro 4.

No conjunto estrutural vigas-laje superior central, existem pontos de infiltração de água por microfissuras que se distribuem paralelas ao encontro viga-laje, além de outros pontos isolados onde há percolação de água com menor vazão, porém com manchas de eflorescência bastante evidentes (Figura 6).

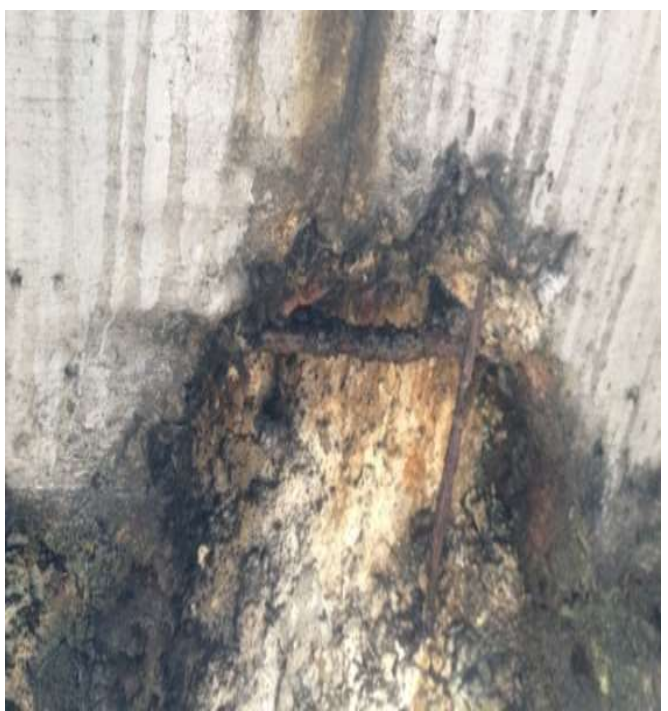

Figura 4: Armadura corroída em falha de concretagem da cinta de coroamento. Fonte: Dos Autores (2017)

Da avaliação das condições da estrutura do Túnel da Abolição, é possível compreender preliminarmente que a estrutura do túnel não apresenta sinais de desplacamento de concreto devido à corrosão de armaduras e, onde há corrosão é devido às falhas de execução.

A presença da eflorescência é indicio de lixiviação do concreto, o que facilita a despassivação por carbonatação. Frente ao exposto é possível compreender que transcorridos 2 anos do uso da estrutura, a mesma se encontra na sua vida útil de projeto, por ainda ter a proteção do cobrimento do concreto nas diversas peças que compõem o túnel, porém, se faz necessário uma inspeção mais detalhada para um diagnóstico conclusivo das condições de desempenho da estrutura do mesmo.

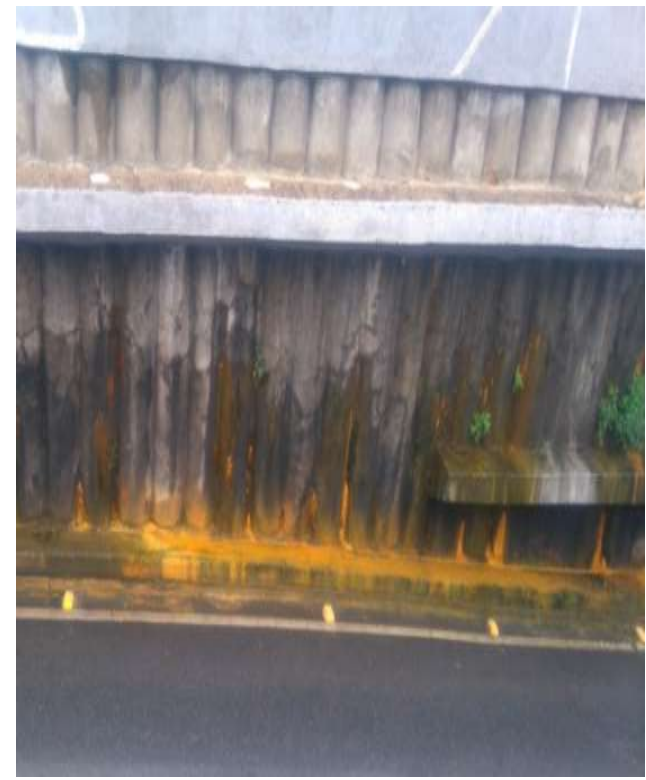

Figura 5: Percolação de água com carreamento da argila sobre a face da parede de contenção Fonte: Dos Autores (2017)

Quadro 4: Resumo das Manifestações Patológicas no Túnel da Abolição

\begin{tabular}{|c|c|}
\hline & Ano 2017 \\
\hline 1 & $\begin{array}{c}\text { Fissuras lineares do tipo mapa no guarda-corpo em } \\
\text { concreto, com algumas apresentando manchas de } \\
\text { eflorescência }\end{array}$ \\
\hline 2 & $\begin{array}{l}\text { Manchas de lodo e bolor por toda a extensão da parede de } \\
\text { contenção }\end{array}$ \\
\hline 3 & $\begin{array}{l}\text { Fissuras tipo mapa na cinta de coroamento da parede de } \\
\text { contenção }\end{array}$ \\
\hline 4 & $\begin{array}{c}\text { Percolação de água e carreamento de material argiloso por } \\
\text { toda a extensão da parede de contenção em estacas } \\
\text { secantes }\end{array}$ \\
\hline 5 & $\begin{array}{c}\text { Eflorescência no conjunto estrutural vigas-laje superior } \\
\text { central }\end{array}$ \\
\hline 6 & $\begin{array}{c}\begin{array}{c}\text { Manchas de percolação de água nas vigas da laje superior } \\
\text { central }\end{array} \\
\end{array}$ \\
\hline 7 & $\begin{array}{c}\text { Nichos de concretagem na cinta de coroamento inferior, } \\
\text { com trechos com armadura exposta }\end{array}$ \\
\hline 8 & $\begin{array}{l}\text { Fissura na interface entre viga-laje superior central e } \\
\text { guarda corpo superior }\end{array}$ \\
\hline 9 & $\begin{array}{c}\text { Drenagem ineficiente na parte sobre o túnel, com acúmulo } \\
\text { de água nos canteiros e nas calçadas }\end{array}$ \\
\hline
\end{tabular}

Fonte: Adaptado de DA FONTE (2011) 


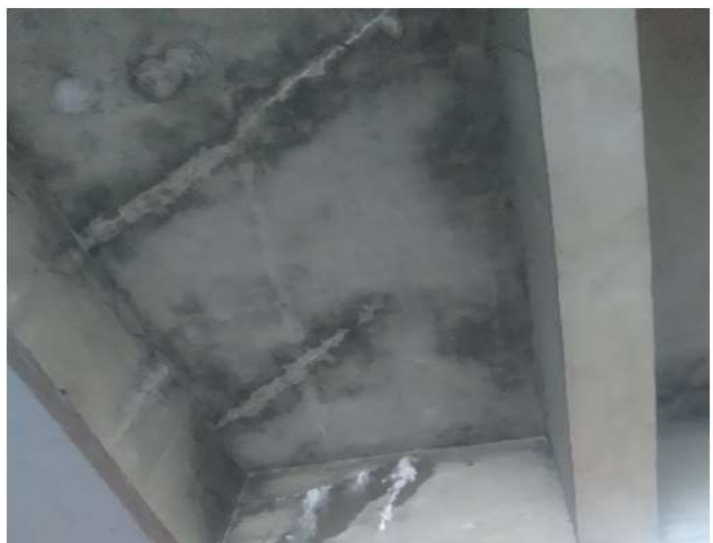

Figura 6: Manchas de eflorescência na laje superior central. Fonte: Autores (2017)

\subsection{Túnel Felipe Camarão}

O túnel Felipe Camarão é o único que está sob a gestão do Governo do Estado de Pernambuco e foi inaugurado em 2012. A contenção lateral é composta por cortinas atirantadas em concreto armado, com trechos ancorados por tirantes e outros travados por vigas. O túnel é composto por quatro faixas, duas na direita no sentido Jordão-Boa Viagem (Oeste-Leste) e duas na esquerda no sentido oposto, bem como calçadas laterais e um canteiro central. Todas as características do Túnel Felipe Camarão podem ser verificadas no Quadro 5.

Quadro 5: Características do Túnel Felipe Camarão

\begin{tabular}{|c|c|}
\hline Ano de Construção & $\mathbf{2 0 1 2}$ \\
\hline Localização & Jordão, Recife - PE \\
\hline Tipo de Túnel & Urbano \\
\hline Proprietário & DER-PE \\
\hline Extensão & $301,00 \mathrm{~m}$ \\
\hline Largura & $8,00 \mathrm{~m}$ \\
\hline Altura Limite & $6,00 \mathrm{~m}$ \\
\hline Quantidade de Faixas & Duas Faixas/Sentido \\
\hline Sentido de Fluxo & Sentido Duplo (Leste-Oeste) \\
\hline Material & Concreto armado \\
\hline Forma & Semienterrado \\
\hline Contenções Laterais & Cortinas atirantadas em concreto \\
\hline armado \\
\hline Tipo de Juntas & Jeene \\
\hline Tipo de Pavimentação & CBUQ \\
\hline
\end{tabular}

Fonte: Adaptado DA FONTE (2011)

Das inspeções visuais, ficou evidente o grande número de fissuras verticais e do tipo mapa nas paredes de contenção tipo cortina atirantada. As 163 fissuras verticais aparecem de forma uniforme e em distâncias similares, evidenciando que são fissuras de alivio. Várias dessas fissuras tinham sinais de percolação de água, e consequentemente presença de lodo, bolor, criptoflorescência, vegetação e carreamento do material do aterro (Figura 7). Nas vigas transversais e longitudinais também foram identificadas fissuras verticais e a $45^{\circ}$ nos trechos mais próximos às cortinas atirantadas, como se pode notar na Figura 8. De um total de 22 vigas transversais, 11 antes da laje central e 11 depois, 6 apresentaram fissuras.

Algumas vigas transversais também apresentam sinais de bolor, manchas de percolação de água e eflorescência.
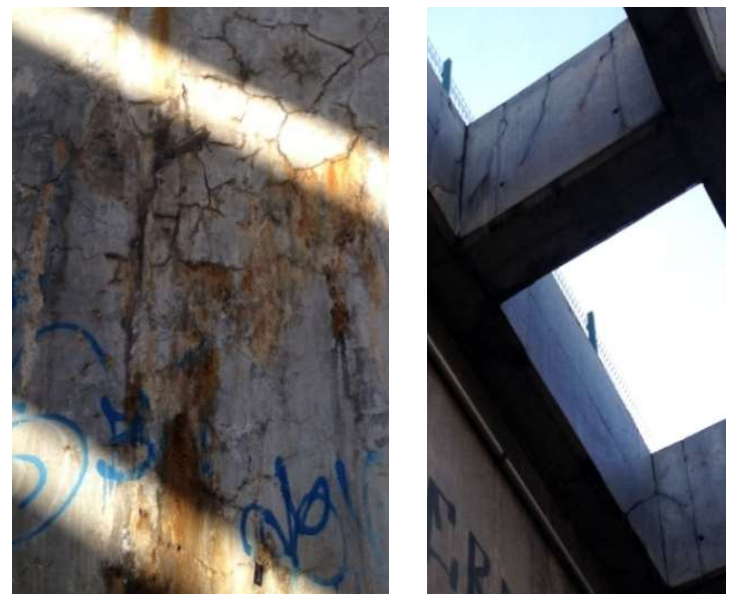

Figuras 7 e 8: Fissuras do tipo mapa com manifestações patológicas; vigas longitudinais e transversais com fissuras a $45^{\circ}$ Fonte: Autores (2017)

A Figura 9 evidencia o estado do canteiro central na cota mais baixa do trecho central do túnel. Pelo que foi observado, a faixa da esquerda está com o sistema de drenagem superficial comprometido, com a consequente ocorrência de alagamentos, os quais são constantes. Para dar escoamento às águas acumuladas em tal faixa, foram retiradas peças do meio-fio e demolido um trecho da calçada, para criar uma canaleta improvisada para escoamento das águas e drena-las até a faixa da direita. Tal medida agravou as condições de drenagem superficial do túnel, uma vez que não resolveu o citado problema.

http: / /dx.doi.org/10.25286/repa.v2i3.712 


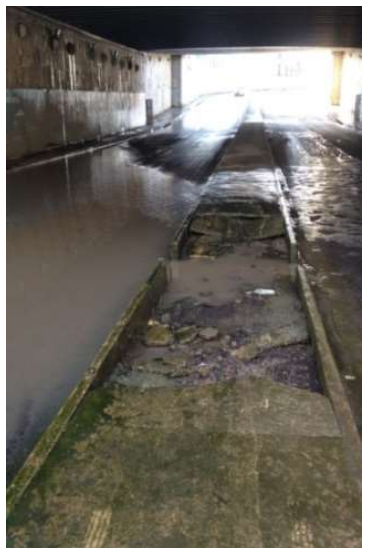

Figura 9: Canteiro Central destruído e alagamento na faixa da esquerda. Fonte: Autores (2017)

No trecho central do túnel, rente à laje superior, foi fixada uma estrutura tipo steel deck, que abrange toda a sua superfície da mesma, inviabilizando a inspeção visual da face inferior da laje.

Esse sistema steel deck-calhas laterais direciona a água para as calhas laterais, que por sua vez conduzem-nas até as caixas de coleta do sistema de drenagem. Apesar de não ter sido possível inspecionar a laje superior do túnel, indícios de manifestações patológicas são aparentes, a exemplo de pontos com manchas de corrosão. O alagamento constante das áreas internas do túnel tem influenciado negativamente as condições da pavimentação asfáltica do túnel, tendo em vista que se observaram ambos os lados com o pavimento bastante degradado, com consequente redução da velocidade do tráfego.

A presença constante de águas de chuva tem ocasionado a formação de lodo nas calçadas, o que é um risco para os pedestres. Os problemas de manutenção no túnel Felipe Camarão estão apresentados no Quadro 6.

Quadro 6: Problemas identificados por falta de manutenção no Túnel Felipe Camarão

\begin{tabular}{|c|c|}
\hline & Ano 2017 \\
\hline 1 & $\begin{array}{l}\text { Grade de proteção do sistema de recalque } \\
\text { danificada }\end{array}$ \\
\hline 2 & Alagamento no ponto mais baixo do Túnel \\
\hline 3 & $\begin{array}{l}\text { Parte do canteiro central destruído devido à água } \\
\text { contida na faixa da esquerda (sentido oeste-leste) }\end{array}$ \\
\hline 4 & Grades acima da cortina de contenção danificadas \\
\hline 5 & $\begin{array}{c}\text { Acúmulo de água de chuva nas ruas laterais ao } \\
\text { túnel }\end{array}$ \\
\hline 6 & Lixo acumulado nas bocas dos bueiros \\
\hline 7 & $\begin{array}{l}\text { Fluxo de água sobre as instalações elétricas do } \\
\text { sistema de iluminação }\end{array}$ \\
\hline 8 & $\begin{array}{c}\text { Presença de vegetação e lodo nas calçadas e } \\
\text { estrutura }\end{array}$ \\
\hline
\end{tabular}

164
Fonte: Dos Autores (2017).

Da observação da Figura 11 é possível perceber o processo inicial de deterioração das calhas e a presença vazamentos na face da cortina de contenção, além do fluxo de água por cima dos eletrodutos do sistema de iluminação. Além das calhas, também é possível observar um revestimento sob a laje superior do túnel do tipo steel deck (Figura 10). O citado revestimento tipo steel deck influencia negativamente a estrutura, visto que pode estar escondendo eventuais manifestações patológicas. As manifestações patológicas estão listadas no Quadro 7.

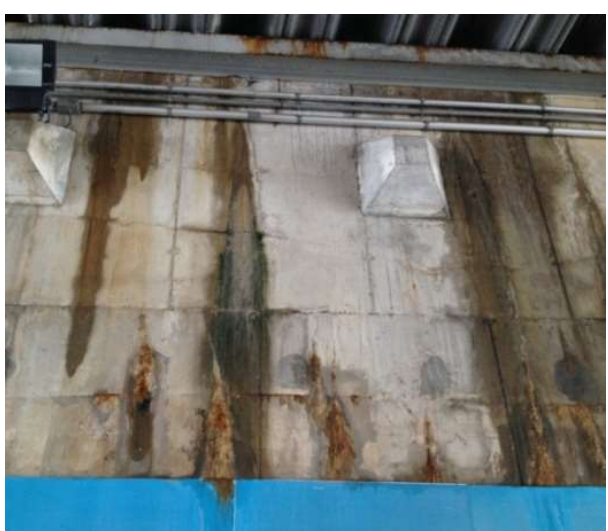

Figura 10: Revestimento tipo steel deck sob a laje superior. Fonte: Autores (2017)

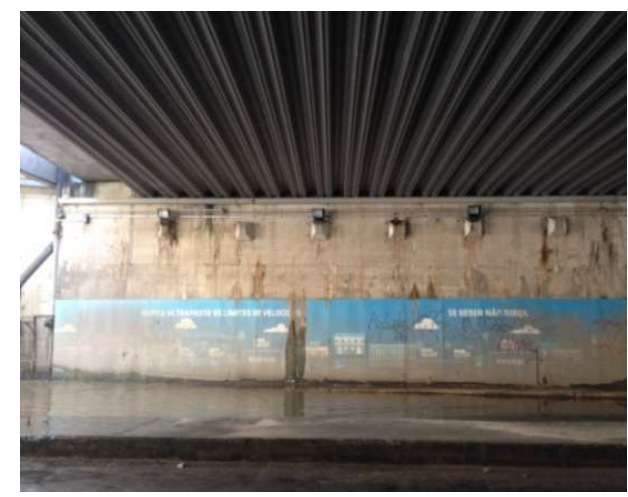

Figura 11: Calha lateral com manchas de potencial corrosão e; vazamento de água sobre a face da cortina. Fonte: Autores (2017)

Da avaliação das condições da estrutura do Túnel Felipe Camarão, é possível compreender preliminarmente que não há manifestações patológicas que possam acelerar o fim da vida útil de projeto do mesmo, porém, se faz necessário uma inspeção mais 
detalhada para um diagnóstico conclusivo das condições de desempenho da estrutura do túnel.

Quadro 7: Resumo das Manifestações Patológicas no Túnel Felipe Camarão.

\begin{tabular}{|c|c|}
\hline & Ano 2017 \\
\hline 1 & $\begin{array}{c}\text { Manchas de percolação de água nas cortinas de contenção, } \\
\text { vigas e laje superior da estrutura }\end{array}$ \\
\hline 2 & $\begin{array}{c}\text { Sinais de corrosão de armadura na região das calhas de } \\
\text { drenagem laterais }\end{array}$ \\
\hline 3 & Eflorescência e criptoflorescência nas cortinas de contenção \\
\hline 4 & Fissuras do tipo mapa e linear nas cortinas de contenção \\
\hline 5 & $\begin{array}{c}\text { Fissuras verticais e a } 45^{\circ} \text { nas vigas longitudinais e } \\
\text { transversais }\end{array}$ \\
\hline 6 & $\begin{array}{c}\text { Presença de lodo e bolor nas calçadas e cortinas de } \\
\text { contenção }\end{array}$ \\
\hline 7 & $\begin{array}{l}\text { Pavimento asfáltico deteriorado com prejuízo para a fluidez } \\
\text { do tráfego }\end{array}$ \\
\hline
\end{tabular}

Fonte: Adaptado DA FONTE (2011)

\section{Conclusões}

As inspeções visuais sinalizam que as estruturas dos dois túneis apresentam sinais de deterioração em estágio inicial, contudo, prematura e acelerada. Manifestações patológicas como fissuras, eflorescência, criptoflorescência, bolor e percolação de água se apresentam dispersas em toda a extensão dos Túneis da Abolição e Felipe Camarão. O Túnel da Abolição, com apenas 2 anos de uso, apresenta sinais de deterioração que requerem ações breves do proprietário para sanar o citado cenário. O Túnel Felipe Camarão também apresenta sinais que exigem ações breves de manutenção. Nas cortinas de contenção há um número expressivo de fissuras em toda a superfície e algumas se prolongam até as vigas de travamento. Uma avaliação completa foi prejudicada pelo revestimento tipo steel deck abaixo da laje, porém há indícios que apontam para a existência de manifestações patológicas na face inferior da laje superior. Os alagamentos também têm prejudicado o revestimento asfáltico, fazendo com que os usuários do túnel o evite em dias de chuva, o que vai de encontro com a proposta inicial de sua construção.

A falta de projeto adequado e a pressa para a execução podem ter sido os fatores cruciais para as estruturas mais recentes estarem em estado similar às mais antigas. A carência de normas técnicas e legislação específica, que estipulem ciclos de inspeções em túneis, exime da responsabilidade o proprietário da estrutura, o poder público, uma vez que a execução de manutenções preventivas não é obrigatória, o que estimula a cultura de intervenção apenas quando o estado da estrutura é crítico. É importante destacar que mesmo sem normas específicas o poder público pode criar programas de manutenção preventiva e inspeções rotineiras, buscando prolongar a vida útil das estruturas e garantir a segurança dos usuários, pois é evidente que se medidas preventivas não forem tomadas a deterioração e os custos de recuperação dos túneis irão acelerar e crescer exponencialmente.

\section{Referências}

[1] DA FONTE, F. J. M. Proposta para um Sistema de Inspeção e Mantenção dos Túneis da Cidade do Recife, CINPAR2011, Fortaleza, Brasil, 2011.

[2] SOARES, R. A $8^{a}$ pior do mundo e a $3^{a}$ do Brasil. Essa é a posição do Recife no ranking das cidades que tem o pior, Jornal do Comécio, Recife, 22 mar. 2016. Portal NE10, De olho no trânsito. Disponível em: http://jc.ne10.uol.com.br/blogs/deolhonotransito /2016/03/22/a-8a-pior-do-mundo-e-a-3a-dobrasil-essa-e-a-posicao-do-recife-no-rankingdas-cidades-que-tem-o-pior-transito/>. Acesso em: 12 de Jun. 2017. 16:32:15.

[3] SOUZA, V. C. M. de; RIPPER, T.; Patologia, Recuperação e Reforço de Estruturas de Concreto. São Paulo: PINI, 2009.

[4] UEDA, T.; TAKEWAKA, K. Performance-based Standard Specifications for Maintenance and Repair of Concrete Structures in Japan. Structural Engineering International, v. 4, p. 359-366, 2007.

[5] ASSOCIAÇÃO BRASILEIRA DE NORMAS TÉCNICAS (ABNT). NBR-6118: Projeto de estruturas de concreto - Procedimento. Rio de Janeiro, 2014. $170 \mathrm{p}$

[6] HELENE, P. R. Vida útil de estruturas de concreto armado sob o ponto de vista da corrosão da armadura. In: SEMINÁRIO DE DOSAGEM E CONTROLE DOS CONCRETOS ESTRUTURAIS, julho a setembro 1993. Anais, Brasília, ENCOL, 1993.

http: / /dx.doi.org/10.25286/repa.v2i3.712 
[7] MEDEIROS, M. H. F.; ANDRADE, J. J. O.; HELENE, P. Durabilidade e Vida Útil das Estruturas de Concreto. In: ISAIA, G. C. Concreto: Ciência e Tecnologia. 1. ed. São Paulo: IBRACON, v. 1, 2011. Cap. 22, p. 773-808.

[9] LEMOS, K. B. Q. (2005). Manutenção e Reabilitação de Túneis, Publicação G.DM138/2005, Departamento de Engenharia Civil e Ambiental, UnB, Brasília, DF, 186 p.

[10] ITA (1991). Report on the Damaging Effects of Water on Tunnels During their Working Life. Tunnelling \& Underground Space technology, 6: 11-76.

[11] DNER. Manual de Inspeção de Obras de Arte Especiais, Rio de Janeiro, 1994. 